\title{
Letter
}

\section{Evaluation of oxidative stress in diabetics with vascular complications}

Microvascular complications in diabetes mellitus results from interaction of multiple metabolic, genetic and other factors, and is an important cause of morbidity and mortality. ${ }^{1}$ There is immense variability in susceptibility to microvascular disease, which in individual patient cannot be predicted from their glycaemic behaviors. ${ }^{1,2}$ Recently many reports indicated that oxidative stress can play a significant role in diabetic complications. ${ }^{2,3}$ The body's protects against the effects of oxidant stress through the role played by enzymes like glutathione peroxidase and catalase, superoxide dismutase whereas in extracellular fluids other antioxidants like ceruloplasmin, urate, vitamin E, ascorbate, are operative. ${ }^{4}$ Thus, assessment of parameters such as malonaldehyde, and glutathione can give an indication of oxidative stress. Moreover, antioxidant vitamins like vitamin E play an important role in protecting the body from oxidative stress.

A total of 59 consecutive patients of noninsulin dependent diabetes mellitus (NIDDM) in the age group of 30-70 years attending diabetic clinic of Pt. B.D. Sharma PGIMS, Rohtak, India were studied and 15 age matched healthy volunteers served as control. Chronic smokers, alcoholics, patients with acute infections, ischaemic heart disease were excluded from the study. An informed consent was taken from these subjects. Thirty diabetic patients were without any complications, 14 were diabetics with retinopathy, 15 had evidences of nephropathy as confirmed by urine examination positive for Red Blood Cells (RBC), Albumin and pus cells. Criterias for achieving glycaemic control were the recommendations of European NIDDM policy group and glycosylated haemoglobin less than $9.5 \%$ was taken as acceptable control of diabetes. Serial blood glucose fasting and postprandial, ${ }^{5}$ and glycosylated haemoglobin (by Stangen's $\mathrm{HBA}_{1} \mathrm{c}$ kit) were estimated. Samples were analysed for malonaldehy'de (MDA), reduced glutathione (GSH), and vitamin E. MDA was analysed by thiobarbituric acid reaction. ${ }^{6}$ GSH was estimated by DTNB reaction. 7 Vitamin $E$ was analysed spectrofluorometrically. ${ }^{8}$ Datas obtained were analysed statistically using student's t-test.
Table 1 lists the mean values and standard deviation of lipid peroxide (MDA), vitamin E and GSH values. Significant changes were observed in diabetic group as compared to control. In this study, patients with diabetes and various diabetic complications had significantly higher MDA levels as compared to normal ( $p<0.001$ ). As for GSH and vitamin E levels, statistically low levels in the diabetics with and without complications were observed as compared to control $(p<0.001)$. Diabetics with complications had higher MDA and lower vitamin E and GSH levels as compared to diabetics without complications. Statistically significant correlations could be observed between MDA and GSH, vitamin E and GSH as well as MDA and vitamin $E(r=-0.96,0.97,-0.99$, respectively $p<$ 0.001 ). Although conventional treatment with diet, insulin, oral hypoglycaemic agents have been successful in ameliorating insulin deficiency and prolong life, it has been unable to prevent the development of chronic complications affecting the vascular and nervous system. Patients with similar levels of chronic hyperglycaemia differ markedly in their susceptibility to the diabetic complications. ${ }^{9}$ Twenty percent to $40 \%$ of long standing diabetic do not develop significant complication, despite poor metabolic control. ${ }^{9}$ Differential susceptibilities are also evident at tissue level. One third of normal kidneys transplanted into diabetics were found to develop renewed severe diabetic nephropathy ${ }^{10}$ suggesting that diabetics possess some humoral factors which can damage tissues, and tissues in different individuals have different resistances to such factors. Moreover, other factors like genetic, environmental, metabolic control of diabetes and other

Table 1. Lipid peroxide, vitamin $\mathrm{E}$ and glutathione levels in controls and diabetics (mean $\pm S D$ )

\begin{tabular}{lccc}
\hline Group & $\begin{array}{c}\text { MDA } \\
(\mu \mathrm{mol} / \mathrm{L})\end{array}$ & $\begin{array}{c}\text { Vitamin E } \\
(\mu \mathrm{mol} / \mathrm{L})\end{array}$ & $\begin{array}{c}\text { GSH } \\
(\mathrm{mg} \%)\end{array}$ \\
\hline $\begin{array}{l}\text { Control }(\mathrm{n}=15) \\
\begin{array}{l}\text { Diabetics without } \\
\text { complication ( }=30)\end{array}\end{array}$ & $2.34 \pm 0.73$ & $5.32 \pm 0.69$ & $8.14 \pm 2.22$ \\
$\begin{array}{l}\text { Diabetic retino- } \\
\text { pathy (n=14) }\end{array}$ & $3.60 \pm 1.63$ & $4.76 \pm 1.40$ & $7.69 \pm 1.34$ \\
$\begin{array}{l}\text { Diabetic nephro- } \\
\text { pathy (n=15) }\end{array}$ & $3.73 \pm 1.53$ & $4.96 \pm 1.45$ & $7.56 \pm 1.54$ \\
\hline
\end{tabular}

Values are significant at all levels $(p<0.001)$ 
undetermined causes make an individual susceptible to vascular complications.

There is also direct evidence that there are elevated levels of oxidants (e.g. peroxides), products of oxidation and rates of free radical generation in diabetics, and that this together with different tissue levels of antioxidant may correlate with the extent of the tissue pathological changes. ${ }^{3,9}$ Different levels of enzymatic and non-enzymatic antioxidants are involved in the different susceptibilities of different tissues and different individuals to this oxidative damage. ${ }^{4}$

In the present study, increased oxidative stress in diabetics with or without complication was observed. Our findings are similar to those reported in literature. ${ }^{3,9}$ Quantitative estimation of free radical products i.e. MDA and glutathione and vitamin E levels may be excellent parameters to judge the metabolic control of diabetes and an excellent guide as a prognostic factor for the development of micro and macro angiopathic complications of diabetes. Thus, it seems that assessment of the level of oxidative stress by above parameters may be useful in identifying diabetic subjects at high risk of developing late complications.

Anjali Sharma, S.N. Chugh ${ }^{*}$, Rajesh Kakkar ${ }^{*}$, Simmi Kharb

Departments of Biochemistry and Medicine ${ }^{*}$, Pt. B.D. Sharma, Postgraduate Institute of Medical Sciences, $\mathrm{H}$ No 1447, Sector-1. Urban Estate. Rohtak - 124001, India

\section{References}

1. Wierusz WB, Wysocki H, Byks A, Zozulinska D, Wykretowicz A, Kazmierczak M. Metabolic control quality and free radical activity in diabetic patients. Diabetes Res Clin Pract 1995; 26:193-7.

2. Young IS, Tate S, Lightbody JH, Mc Master D, Trimble ER. The effects of desferrioxamine and ascorbate on oxidative stress in streptozocin diabetic rats. Free Radic Biol Med $1995 ; 18: 833-40$.

3. Bavnes JW. Role of oxidative stress in the development of complications in diabetes. Diabetes 1991; 40:405-12.

4. Dormandy TL. An approach to free radicals. Lancet 1983; 2:1010-4.

5. Trinder P. Determination of blood glucose using a oxidase peroxidase system with non-carinogenic chromogen. J Clin Path 1969; 22:158-61. 